\title{
Analysis of Research Trends on North Korean Defector Children
}

\author{
Young Suk Yong, Suk Ja Kim \\ Department of Early Childhood Education, Korea National University of Education, Chung-Buk, Korea
}

탈북 아동에 관한 연구 동향 분석

용영숙, 김숙자

한국교원대학교 유아교육과

Objective: The aim of this study was to analyze the research trends on North Korean defector children.

Methods: A total of 127 related research papers were analyzed according to their publication year, children's age, research area, topic, and method.

Results: First, the study analyzed the research papers according to publication year and found that there was a rising tendency in their quantity since 1999, when the first study was published; additionally, we found that 12 or more research papers have been published annually since 2012, except for 2017. Second, concerning children's age, there were more papers on children in the school ages than children in early childhood. Third, the most popular research area was human ecology (22.83\%), followed by education (19.69\%), and psychological sciences (18.90\%). Fourth, the most frequent research topic was family/welfare (28.35\%), followed by psychology/sexuality/counseling (20.47\%), and education/activities (16.54\%). Fifth, the most popular methods were qualitative research (28.35\%), survey research (27.56\%), and experimental study $(18.90 \%)$.

Conclusion: First, there is a need to expand research on young North Korean defector children. Second, expanding research on fathers as parents is also essential. Third, it is necessary to develop teaching-learning methods and welfare programs applicable to the field with various members of society, including North Korean defector children. Fourth, studies need to examine the lives and changes of North Korean defector children from a long-term perspective beyond short-term research. Finally, comparative studies on the unique characteristics of North Korean defector children should be performed according to their diverse backgrounds and experiences.

Keywords: North Korean defector children, research trends$$
\text { 서론 }
$$

남한사회로 이주하는 북한이탈주민의 누적수가 꾸준히 증가 하고 있다. 2001 년 북한이탈주민의 누적 입국인원은 1,043 명 이었으나 2017에는 30,490명으로 증가하였다는 Ministry of Unification (2017)의 자료는 이같은 현상을 알게 한다. 흥미로

Corresponding Author: Suk Ja Kim, Department of Early Childhood Education, Korea National University of Education, 59, Seopgol-gil, lochiwon-eup, Sejong-si, Republic of Korea

E-mail: ksjknue@knue.ac.kr
\end{abstract}

운 것은 북한이탈주민의 누적수 증가와 더불어 이주를 하게 되는 원인의 변화이다. 과거에는 경제적 요인이나 정치체제에 대한 불만이 주요 원인(Ministry of Unification, 2017)이었으나 최근에는 '자녀에게 좋은 미래를 주기 위해' 자녀와 동반하여 탈북 하는 사례가 많아졌다는 것이다(Korea Hana Foundation, 2016). 이같은 현상은 2016년을 기준으로 하나원(북한이탈주

(C)The Korean Association of Child Studies

This is an Open Access article distributed under the terms of the Creative Commons Attribution Non-Commercial License (http:// creativecommons.org/licenses/by-nc/4.0) which permits unrestricted noncommercial use, distribution, and reproduction in any medium, provided the original work is properly cited. 
민정착지원사무소)의 하나둘학교에서 유치반(만 3-5세) 교육 을 받은 유아의 수가 하나둘학교 전체 학생의 약 $16 \%$ 를 차지 하고 있으며 초등학생은 $29 \%$ 로, 전체 학생 중 유아부터 초등 학생의 아동이 약 $45 \%$ 의 비율을 차지하고 있다는 자료에 의 해 뒷받침되고 있다.

새로운 삶에 대한 기대와 희망을 안고 입국하는 탈북 아 동은 증가하고 있지만, 낮선 사회와 문화에 적응하는 과정에 서 아동들은 여러 가지 어려움을 겪을 수 있다. 이와 관련된 탈북 아동 연구들은 지속적으로 있어왔다(S.-H. Kim, 2017; M. J. Kim, 2014; Y. Y. Kim, 2002; H. J. Kim, 2015; Korea Hana Foundation, 2017; G.-H. Yoo, Bang, \& Han, 2004; B.-M. Lee, 2003). 선행연구들에 따르면, 탈북 아동들은 탈북의 과정에서 가족해체는 물론 신변의 위험, 굶주림과 같은 어려움을 겪게 되는데, 이 기간 동안 억눌린 욕구와 감정이 남한 사회 적응 기 간 동안 분출됨으로써 또래와의 관계 형성에 어려움을 겪는다 (B.-M. Lee, 2003). 특히 어머니와 분리를 경험한 유아의 경우, 거부당하는 것에 대한 두려움 때문에 대인관계에서 회피적 성 향을 갖게 되는 경향이 있다고 보고되었다(H. J. Kim, 2015). 또한 새로운 환경에 적응하는 동안 불안, 열등감, 소외감, 정체 성 혼란과 같은 심리.정서적 문제를 경험하기도 하며 심각한 경우, 외상후 스트레스 장애로 고통 받기도 한다(S.-H. Kim, 2017).

초등학령기 이상의 탈북 아동의 경우에는 학교에 진학하 게 되면서 사회적 관계나 학업에 대한 더 많은 고민을 하게 된 다. 학급 내에 존재하고 있는 고정관념과 편견은 탈북 아동들 이 보이는 행동을 ‘문제아’나 ‘반항아’의 일탈 행동으로 규정 하여 탈북 아동의 원만한 적응을 방해할 수 있으며, 반대로 그 들에 대해 갖는 지나친 호기심과 동정심 역시 탈북 아동들을 타자화(他者化) 하는데 기여할 소지가 있다(Y. Y. Kim, 2002; G.-H. Yoo et al., 2004; M. J. Kim, 2014). 이러한 심리.정서적 인 어려움과 함께 교육 공백으로 인한 학업 부진의 문제는 탈 북 아동에게 가장 큰 고민거리로 인식되고 있는데(Korea Hana Foundation, 2017), 이는 학교와 사회 부적응의 문제를 발생시 키는 요인으로 작용하기도 한다.

하지만 이러한 어려움에도 불구하고, 탈북 아동들은 자 신에게 주어진 환경에 적응해 나가며 건강한 발달을 이뤄가 는 회복력을 발휘한다. 특히 어린 시기에 남한에 정착한 아동 일수록 새로운 문화에 빠르게 적응하는 양상을 보였는데(J. Kang, 2010) 이는 발달의 '가소성(plasticity)'에 의한 것이라 사 료된다. 가소성이란 삶의 경험에 반응하여 변화할 수 있는 역 량으로, 일반적으로 어린 연령일수록 결함을 회복할 수 있는
역량이 더 큰 것으로 알려져 있다. 또한 이러한 개인적 요인 외 에도, 부모를 비롯한 가정과 또래 및 교사로부터 받는 사회적 지지 역시 적응의 보호요인으로 작용하여 탈북 아동의 건강 한 발달을 돕는데 기여하는 것으로 보인다(Kang, 2008; J.-H. Park, 2008; Y. M. Kim, 2002).

이보다 더 나아가 우리 사회가 탈북 아동의 적응과 발달을 돕는 지지체계로 작용하기 위해서는 탈북 아동에 대한 다양한 연구를 통해 그들의 특성 및 배경을 정확하게 이해하고 진단 하는 것이 선행되어야 할 것이다. 이에 따라 1990 년대 후반부 터 지금까지 탈북 아동 및 북한이탈주민에 관한 기초연구들이 실행되고 있으며, 2011년부터는 이에 대한 동향연구도 이루 어지기 시작했다. 특히 동향연구는 지금까지 이루어진 연구의 추이를 분석하고 향후 방향을 제시한다는 측면에서, 궁극적으 로 탈북 아동 연구 분야의 질적 발전에 기여하게 될 것이다.

이러한 필요에 따라 탈북 아동 및 북한이탈주민 연구 분야 에서는 2011년 Choi와 Park (2011)의 정책연구 동향 분석을 시 작으로 북한이탈주민에 대한 동향 분석이 이루어지기 시작했 다(G. T. Park, 2014; J.-R. Park \& Kang, 2011; Yang \& Yun, 2017; M. Y. Lee, 2015; Choi \& Park, 2011; Huh, Yi, Han, O, \& Jung, 2017). 동향 분석 연구들을 구체적인 성격에 따라 분석하면, 북한이탈주민의 정착 및 적응에 관한 연구(G. T. Park, 2014; M. Y. Lee, 2015), 정책과 교육분야에 관한 연구(Choi \& Park, 2011; Huh et al., 2017), 정신건강에 관한 연구(Yang \& Yun, 2017), 탈북 여성에 관한 연구(J.-R. Park \& Kang, 2011), 탈북 청소년에 관한 연구(Yun, 2014)가 있다. 이 같은 동향 연구들 에서 분석되는 특징은, 성인만을 연구 대상으로 설정하였거나 학령기 학생에서 성인에 이르는 대상들을 포괄하여 분석하였 다 것에 있다. 이는 특정한 발달 시기를 대상으로 하는 연구의 동향을 구체적으로 파악하기 어렵다는 한계를 보인다.

비록 탈북 청소년만을 대상으로 한 동향 연구가 이루어지 긴 하였지만 이 역시도 만 7세에서 24세에 이르는 청소년을 대상으로 했기 때문에 청소년 초기 즉, 초등학령기에 해당하 는 아동기에 대한 연구 동향을 파악하는 것에는 한계가 있다. 발달심리학적으로 청소년 초기와 중기, 말기에는 각각 다른 특성과 요구를 가지게 되므로, 청소년 초기에 해당하는 아동 기에 대한 연구 동향 분석을 통해 그들을 지원할 수 있는 향후 연구의 방향을 제시할 필요가 있다. 특히, 그동안의 동향 연구 에서는 제외되었던 '유아기' 아동에 관한 연구도 포함함으로 써 선행연구들과의 차별성 있는 연구가 이루어져야 할 것으로 보인다. 이에 따라 본 연구는 국내 탈북 아동에 관한 연구 동향 을 알아보고자 한다. 본 연구에서 정의한 '탈북 아동'이란, 한 
명 이상의 북한이탈주민을 부모로 둔 유아기와 초등학령기 아 동으로서 출생지와 상관없이 현재 대한민국(남한)에 주거지 를 두고 있는 아동을 의미한다.

\section{연구 문제 1}

탈북 아동 연구들에서 매 연도별 학위 및 학술지 논문 발표 현 황은 어떠한가?

\section{연구 문제 2}

탈북 아동 연구들에서의 연구대상 아동 관련 학령별 분포는 어떠한가?

\section{연구 문제 3}

탈북 아동 연구들에서의 연구 분야는 어떠한가?

\section{연구 문제 4}

탈북 아동 연구들에서의 연구 주제는 어떠한가?

\section{연구 문제 5}

탈북 아동 연구들에서의 연구 방법은 어떠한가?

\section{연구방법}

\section{탈북 아동 연구의 동향분석을 위한 자료 수집}

탈북 아동 연구의 동향분석을 위한 논문의 수집은 2017년 7 월부터 한 달간 학술연구정보서비스(http://www.riss.kr/)와 국 회도서관(http://www.nanet.go.kr/)을 통하여 '북한이탈주민 아 동', ‘북한이탈주민 유아', '탈북 아동', ‘탈북 유아', '새터민 아 동', '새터민 유아', '북한이탈 아동', '북한이탈 유아'와 같은 키 워드를 사용하여 이루어졌고, 추출된 352 개의 논문들 중 다음 과 같은 6 가지 선정 기준에 따라 132 편이 1 차 연구 대상으로 선정되었다.

1 차 연구대상 선정 기준은 다음 여섯 가지와 같다. 첫째, 탈 북 아동을 연구한 국내 논문으로 한다. 둘째, 탈북 청소년과 관 련된 연구 중 본 연구가 대상으로 하는 연령의 아동이 포함된 경우, 연구대상으로 인정한다. 셋째, 다문화 관련 연구 중 탈북 아동을 독립적인 연구대상으로 설정한 경우, 연구대상으로 인 정한다. 넷째, 탈북 아동의 부모, 교사, 또래를 대상으로 한 연 구를 포함한다. 다섯째, 탈북 아동을 소재로 한 문학작품 연구
를 포함한다. 여섯째, 학위 논문을 수정하여 학술지 논문으로 등재한 경우, 학위 논문을 중심으로 통합한다. 이와 같은 기준 으로 1 차에서 선정된 132 편의 논문들 중에서 저자의 요청으 로 인해 연람 불가 상태인 5 편의 논문을 제외하여 최종 127 편 의 논문을 연구 대상으로 하였다.

\section{동향 분석을 위한 분석 준거 및 내용}

탈북청소년과 북한이탈주민, 아동.청소년을 대상으로 한 동 향 분석 관련 선행연구들(M. H. Lee, 2011; Y. S. Lee, Son, \& Choi, 2012; Y. M. Lee, 2015)을 중심으로 정리한 결과, 연구 발 표 연도, 연구 대상 아동의 학령, 연구 분야, 연구 주제, 연구 방 법의 다섯 가지 분석 준거 및 내용들을 추출하였다.

이 같은 분석 준거 및 내용들을 추출하기 위하여 연구 동향 분석 관련 유경험자인 박사과정생 1 인이 참여하여 연구 기준 을 분석, 검토하였다. 또한 연구자 2 인은 분석 기준에 따라 개 별적으로 자료를 분류한 후 결과를 비교하였으며, 이 때 불일 치하는 내용은 협의를 통해 일치된 결과를 도출하였다. 분류 기준 별 세부 내용을 정리하면 다음의 다섯 가지로 요약된다.

\section{발표 연도별 현황}

발표 연도별로 논문을 분류함으로써 시간의 흐름에 따른 연구 현황을 분석한다. 연도는 탈북 아동 연구가 처음 발표되기 시 작한 1999년부터 최근 2017년까지 1년 단위로 분류하되, 학위 논문과 학술지 논문을 분리하여 분석한다.

\section{연구 대상 아동의 학령별 분포도}

연구 대상 아동의 학령별 분포는 다음과 같은 세 가지 기준을 통해 분석한다. 첫째, 발달 심리학적인 특성과 한국 사회 내에 서 부과하는 발달 과업에 따라 유아기 및 초등학령기로 구분 하여 분석한다. 유아기와 초등학령기의 아동을 동시에 연구 대상으로 설정한 경우, 이를 별도로 분류하여 분석한다. 둘째, 탈북 아동의 경우, 학력손실로 인해 실제 나이보다 더 어린 연 령의 학년으로 배정되는 경우가 많아, 실제로는 초등학생 연 령 이상이라 하더라도 초등학교에 재학하는 경우가 있다. 이 러한 아동을 대상으로 하는 연구도 포함하되, 재학 중인 학년 을 기준으로 분류한다. 셋째, 탈북 아동의 부모, 교사를 대상으 로 한 논문의 경우, 표집된 연구 대상(부모 또는 교사)의 자녀 또는 학생(탈북 아동)의 학령을 파악하여 분석한다. 


\section{연구 분야별 분포도}

연구 분야의 분류는 논문 저자의 전공에 따라 분류하는 방법 도 있으나 전공의 명칭이 논문의 연구 분야를 설명하기엔 너 무 포괄적이라는 한계가 있어 본 연구에서는 한국연구재단이 개발한 학술연구분야분류표(National Research Foundation of Korea [NRF], 2016)를 기준으로 하여 대분류와 중분류에 의한 세부내용으로 유목화 하였다.

\section{연구 주제별 분포도}

연구 주제의 분석 기준은 황진구, 임지수가 제시한 청소년 연 구 주제 분석 기준을 Yun (2014)이 탈북청소년 연구에서 수정 - 보완한 것을 중심으로 사용하였으며, 대분류와 세부 주제의 내용을 아동 관련 연구에 적합하게 삭제하거나 첨가하여 총 8 가지의 대분류 체계로 정리하였다.

이는 다음과 같은 세 가지 절차에 의해 수행되었다. 첫째, 연 구자 2인은 개별적으로 기존의 연구 주제 분석 기준을 본 연구 의 취지에 맞게 수정. 보완하였다. 둘째, 각각의 수정. 보완 내 용 중 공통된 것을 추출하여 수정 사항에 반영하였다. 이와 관 련된 내용을 구체적으로 살펴보면, '청소년’이라는 표현을 '아 동'으로 대체하였으며, 대분류 체계 중 '청소년 노동.직업'을 삭 제하고 '교육·활동'의 세부 주제에 '진로'의 내용을 포함하였다. 또한 기존 대분류 체계에는 없었던 '기타'를 추가하였다. 마지 막으로, 한 명의 연구자에 의해서만 제시된 수정·보완 사항에 대해서는 연구자 2 인과 박사과정생 1 인이, 사전에 수집된 탈북 아동 연구 목록을 확인하며 논의하는 과정을 통해 반영 여부를
결정하였다. 이러한 과정을 통해 수정·보완된 사항은 총 세 가 지로 첫째, 기존 대분류 체계에 '건강'을 추가하였다. 둘째, 대분 류 중 '의식·문화·사회'에 세부 주제로 '놀이', ‘또래관계'를 첨가 하였으며 셋째, '가정.복지' 대분류에 '가족사', '양육', '부모교 육', '가족 내 상호작용', '가족 지지체계'의 세부 주제를 첨가하 였다. 이에 따른 최종 분류표는 아래의 Table 1 과 같으며, 논문 을 분류 시엔 대분류 체계를 중심으로 분류하였다.

\section{연구 방법별 분포도}

연구 방법 기준 설정을 위해, 탈북 아동 연구와 연관성이 높 은 기존 동향 연구(Yun, 2014; M. H. Lee, 2011; Y. S. Lee et al., 2012; Y. M. Lee, 2015)를 참고하여 조사 연구, 실험 연구, 비교 연구, 문헌 연구, 질적 연구, 개발 연구, 혼합 연구로 총 7가지 의 연구 방법 유형을 추출하였다. 이 중 문헌연구는 기초자료 조사 등 보조적인 성격으로 이루어진 경우를 제외하고 주된 연구 방법으로 사용된 경우만을 인정한다. 또한 혼합연구는 두 가지 이상의 연구 방법을 주된 연구 방법으로 채택하여 사 용한 경우를 의미하며, 논문에 이러한 내용이 기재되었을 시 혼합연구에 포함하였다.

\section{연구결과}

\section{연도별 학위 및 학술지 논문 발표 현황}

탈북 아동 연구들이 발표된 연도별 현황을 분석한 결과는 아

Table 1

Research Themes on North Korean Defector Children

\begin{tabular}{|c|c|c|}
\hline & Main category & Detailed topics \\
\hline 1 & General policy & Policy, child tutor, teacher \\
\hline 2 & Psychology $\cdot$ Sexuality $\cdot$ Counseling & $\begin{array}{l}\text { Psychology, psychological adjustment, counseling, psychotherapy, psychological trauma, } \\
\text { mental health }\end{array}$ \\
\hline 3 & Consciousness $\cdot$ Culture $\cdot$ Society & $\begin{array}{l}\text { Consciousness, cultural/social adaptation, socialization, identity, language, play, peer } \\
\text { relationship, consumer life, social aspects }\end{array}$ \\
\hline 4 & Family . Welfare & $\begin{array}{l}\text { Family history, nurture, home education, parent education, family interactions, family } \\
\text { support system, general welfare, multicultural welfare }\end{array}$ \\
\hline 6 & Behavioral problems $\cdot$ Delinquency & Behavioral problems, delinquent behavior \\
\hline 7 & Health & $\begin{array}{l}\text { Health and disease, nutrition, hygiene, physical development, dental hygienist, health } \\
\text { education }\end{array}$ \\
\hline
\end{tabular}


래의 Table 2와 같다.

Table 2에 의하면, 탈북 아동 연구의 발표 연도 현황은 세 가 지 특징으로 분류할 수 있다. 첫째, 탈북 아동의 연구가 시작 되는 시기로, 1999년에 처음 발표되기 시작한 이후로 2007년 까지 매해 5편 이내의 논문이 발표되었다. 둘째, 탈북 아동 연 구 수의 급등기로, 13 편의 논문이 발표된 2008년이 이에 해당 된다. 비록 이듬해인 2009년에 5편으로 논문의 수가 줄어들긴 했지만, 그 이후로도 2011년까지 발표되는 논문의 수는 꾸준 히 증가하는 추세를 보이고 있다. 셋째, 연구의 수가 유지되는 시기로, 2012년 이후부터는 매해 12 편 이상의 논문이 발표되 고 있으며 그러한 추세가 5년 동안 유지되고 있다. 2017년의 현황은 본 연구의 자료 수집 기간인 7월까지 발표된 논문의 수 이다.

Table 2

Number of Papers by Year

\begin{tabular}{cccc}
\hline Year & Paper for a degree & Journal & Sum $(\%)$ \\
\hline 1999 & 1 & - & $1(0.78)$ \\
2000 & - & - & - \\
2001 & 1 & - & $1(0.78)$ \\
2002 & 3 & 1 & $4(3.15)$ \\
2003 & 1 & 2 & $3(2.36)$ \\
2004 & 3 & 2 & $5(3.94)$ \\
2005 & 2 & 1 & $3(2.36)$ \\
2006 & 2 & 2 & $4(3.15)$ \\
2007 & 1 & 4 & $5(3.94)$ \\
2008 & 6 & 7 & $13(10.24)$ \\
2009 & 2 & 3 & $5(3.94)$ \\
2010 & 4 & 3 & $7(5.51)$ \\
2011 & 3 & 6 & $9(7.09)$ \\
2012 & 9 & 3 & $12(9.45)$ \\
2013 & 9 & 4 & $13(10.24)$ \\
2014 & 7 & 5 & $12(9.45)$ \\
2015 & 5 & 7 & $12(9.45)$ \\
2016 & 5 & 57 & $12(9.45)$ \\
2017 & 6 & & $600)$ \\
\hline Sum (\%) & 70 & $5.72)$ \\
\hline
\end{tabular}

\section{연구 대상 아동의 학령별 분포도}

연구가 대상으로 하는 아동의 학령별로 논문을 분석한 결과는 아래의 Table 3 과 같다.

Table 3에 의하면, 연구들이 대상으로 하고 있는 아동의 학 령은 네 가지 범주로 분류될 수 있는데, '유아기'와 '초등학령 기', ‘유아기와 초등학령기'의 아동을 모두 다룬 연구, 그리고 대상 아동의 학령을 추정하기 어려운 '기타'로 분류할 수 있다. 이러한 네 가지 범주에 따라 분석한 결과는 다음과 같다.

첫째, 유아기를 대상으로 한 논문에 비해 초등학령기를 대 상으로 한 논문이 많은 것으로 분석되었다. 총 127 편의 논문 중, 초등학령기 아동을 대상으로 하는 논문은 74편(58.27\%) 으로 가장 많았고, 유아기 아동을 대상으로 하는 논문은 29편 (22.83\%)이었으며, 유아기와 초등학령기 아동을 모두 다룬 논 문은 20편(15.75\%), 기타는 4편(3.15\%)으로 분석되었다. 즉, 초 등학령기 아동을 대상으로 하는 논문의 수는 유아기 아동을 대 상으로 하는 논문보다 약 2.5 배 정도 많은 것으로 분석되었다.

둘째, 초등학령기 논문의 경우, 탈북 아동을 직접적인 연구 대상으로 설정하는 경향이 강한 반면 유아기 논문의 경우, 탈 북 아동 자체를 연구 대상으로 삼기보다는 그와 관계를 맺고 있는 부모, 교사, 또래를 직접적인 연구 대상으로 설정하는 경 향이 강하였다. 초등학령기 논문은 74편 중 7편의 논문만이 부모·교사. 또래를 대상으로 하고 있었으나 유아기 논문은 29 편 중 20 편의 논문이 부모·교사. 또래를 대상으로 하고 있었 다. 이처럼 유아기 논문은 초등학령기 논문에 비해 매우 소수 의 논문만이 탈북 아동을 직접적인 대상으로 설정하고 있었으 며, 부모 - 교사 - 또래 등 타자와의 관계 속에서 탈북 아동을 이 해하려는 노력이 많은 것으로 분석되었다.

\section{연구 분야별 분포도}

탈북 아동 연구들이 이루어진 연구 분야는 학술연구분야분류 표(NRF, 2016)의 8가지 대분류와 152의 중분류 중, Table 4 와 같이 5 가지의 대분류와 16 가지의 중분류 범주에서 이루어진 것으로 분석되었다.

Table 3

Number of Papers by Children's Age (\%)

Early childhood,

Age of subject children Early childhood Elementary school ages Elementary school ages
$29(22.83)$

$74(58.27)$
$20(15.75)$

Etc. Sum 27 (100) 
Table 4

Number of Papers by Research Field (\%)

\begin{tabular}{|c|c|c|c|}
\hline Main category & Subcategory & $n(\%)$ & Sum $(\%)$ \\
\hline \multirow[t]{3}{*}{ Humanities } & Christian theology & $1(0.79)$ & $6(4.72)$ \\
\hline & Literature & $4(3.15)$ & \\
\hline & Linguistics & $1(0.79)$ & \\
\hline \multirow[t]{8}{*}{ Other humanities } & Sociology & $10(7.87)$ & $79(62.20)$ \\
\hline & Social welfare & $8(6.30)$ & \\
\hline & Anthropology & $1(0.79)$ & \\
\hline & Education & $25(19.69)$ & \\
\hline & Law & $1(0.79)$ & \\
\hline & Public policy & $9(7.08)$ & \\
\hline & Journalism and broadcasting & $1(0.79)$ & \\
\hline & Psychological science & $24(18.90)$ & \\
\hline Natural sciences & Human ecology & $29(22.83)$ & $29(22.84)$ \\
\hline \multirow[t]{3}{*}{ Medicine and pharmacy } & $\begin{array}{l}\text { Preventive medicine/Occupational } \\
\text { and environmental medicine }\end{array}$ & $4(3.15)$ & $12(9.45)$ \\
\hline & Psychiatry & $6(4.72)$ & \\
\hline & Dentistry & $2(1.57)$ & \\
\hline \multirow[t]{2}{*}{ Arts and kinesiology } & Dance & $1(0.79)$ & $1(0.79)$ \\
\hline & m (\%) & & $127(100)$ \\
\hline
\end{tabular}

탈북 아동 연구들을 연구 분야별로 분류 시에는 다음과 같 은 절차에 의해 분류되었다. 첫째, 연구자 2 인은 개별적으로 학술연구분야분류표에 근거하여 연구들을 분류하였다. 둘째, 두 연구자간 일치하지 않는 내용에 대해서는 박사과정생 1 인 을 포함한 3 인이 논문의 내용을 읽어본 후 논의하는 과정을 통 해 합의된 결과를 도출하였다. 예를 들어, '미술치료가 내적 스 트레스 감소와 학교 적응에 미치는 영향: 탈북 아동을 중심으 로(Song, 2008)'와 같은 연구의 경우, '심리과학' 분야와 '교육 학' 분야 중, 논의를 통해 ‘심리과학' 분야로 분류하였다.

Table 4 에 의해, 연구 분야의 대분류와 중분류의 범주로 나 누어 분석하면 다음과 같다.

첫째, 논문들의 연구 분야를 대분류 범주에 의해 분석한 결 과, 사회과학 분야와 자연과학 분야에서 많은 연구들이 이루 어지고 있었음을 알 수 있었다. 특히 사회과학 분야에서 다수 의 연구가 진행되었는데, 전체 127 편의 논문 중 $62.20 \%$ 에 해 당하는 79편의 논문이 사회과학 분야로 분석되었다. 뒤를 이 은 자연과학(22.83\%) 분야와 합하면 약 $85 \%$ 의 논문이 두 연 구 분야에 속한다고 볼 수 있다. 이러한 결과를 통해, 사회과학 분야와 자연과학 분야는 탈북 아동 연구 분야의 큰 맥을 차지 하고 있는 것으로 분석되었다.

둘째, 논문들의 연구 분야를 중분류 범주에 의해 분석한 결
과, 생활과학(22.83\%)과 교육학(19.69\%), 심리과학(18.90\%) 분야에서 많은 연구가 이루어졌다는 것을 알 수 있었다. 대분 류 범주인 자연과학 분야에서 수행된 연구는 모두 생활과학 분야에서 수행되었는데, 생활과학 분야의 경우 가족학이나 아 동발달·보육 및 청소년학을 포함하는 아동학 분야의 연구가 많아 빈도수가 높게 측정되었고 영양학 분야에서도 연구가 이 루어졌다. 이와 마찬가지로 교육학과 심리과학 분야에서도 다 수의 연구가 이루어지고 있었다.

셋째, 다양한 연구 분야에서 탈북 아동을 이해하기 위한 시 도가 이루어지고 있다. 비록 소수이긴 하지만 기독교신학, 언 어학, 인류학, 법학, 신문방송학, 무용 분야에서도 각 1편씩 $(0.79 \%)$ 의 논문이 발표되면서, 다양한 분야에서 탈북 아동에 대한 연구가 이루어지기 시작하였다는 것을 알 수 있다. 시간 의 흐름에 따른 연구 분야의 추이는 Table 5 를 통해 구체적으 로 살펴볼 수 있다.

Table 5에 의하면, 제 1 기간(1999-2003년)에서 제4기간 (2014-2017년)에 이르기까지 사회과학 연구 분야에서 지속 적으로 최다수의 논문이 발표되고 있다. 특히 제 2 기간(20042008년)에서 제3기간(2009-2013년)에 이르는 시기에는 사회 과학 분야에서 압도적으로 많은 수의 논문이 발표되었다는 것 을 확인할 수 있다. 
Table 5

Number of Papers by Research Field and Year

\begin{tabular}{|c|c|c|c|c|c|c|}
\hline Research field & Year & $\begin{array}{c}\text { The } 1 \text { period } \\
1999-2003\end{array}$ & $\begin{array}{l}\text { The } 2 \text { period } \\
2004-2008\end{array}$ & $\begin{array}{l}\text { The } 3 \text { period } \\
2009-2013\end{array}$ & $\begin{array}{l}\text { The } 4 \text { period } \\
2014-2017\end{array}$ & \\
\hline Main category & Subcategory & (5 years) & (5 years) & (5 years) & (4 years) & Sum \\
\hline \multirow[t]{3}{*}{ Humanities } & Christian theology & 0 & 0 & 1 & 0 & 1 \\
\hline & Literature & 0 & 1 & 0 & 3 & 4 \\
\hline & Linguistics & 0 & 0 & 1 & 0 & 1 \\
\hline Sum of humanities & & 0 & 1 & 2 & 3 & 6 \\
\hline \multirow[t]{8}{*}{ Other humanities } & Sociology & 2 & 4 & 1 & 3 & 10 \\
\hline & Social welfare & 2 & 3 & 2 & 1 & 8 \\
\hline & Anthropology & 1 & 0 & 0 & 0 & 1 \\
\hline & Education & 3 & 6 & 10 & 6 & 25 \\
\hline & Law & 0 & 0 & 0 & 1 & 1 \\
\hline & Public policy & 0 & 0 & 7 & 2 & 9 \\
\hline & Journalism and broadcasting & 0 & 1 & 0 & 0 & 1 \\
\hline & Psychological science & 0 & 7 & 12 & 5 & 24 \\
\hline Sum of other humanities & & 8 & 21 & 32 & 18 & 79 \\
\hline Natural sciences & Human ecology & 1 & 6 & 7 & 15 & 29 \\
\hline Sum of natural science & & 1 & 6 & 7 & 15 & 29 \\
\hline \multirow[t]{3}{*}{ Medicine and pharmacy } & $\begin{array}{l}\text { Preventive medicine } \\
\text { /Occupational and environmental } \\
\text { medicine }\end{array}$ & 0 & 1 & 2 & 1 & 4 \\
\hline & Psychiatry & 0 & 1 & 1 & 4 & 6 \\
\hline & Dentistry & 0 & 0 & 1 & 1 & 2 \\
\hline Sum of medicine and pharmacy & & 0 & 2 & 4 & 6 & 12 \\
\hline Arts and kinesiology & Dance & 0 & 0 & 1 & 0 & 1 \\
\hline Sum of arts and kinesiology & & 0 & 0 & 1 & 0 & 1 \\
\hline Sun & (Total) & 9 & 30 & 46 & 42 & 127 \\
\hline
\end{tabular}

이와 함께 눈 여겨 봐야 할 것은, 시간이 흐름에 따라 사회 과학 분야 외의 다른 연구 분야에서 탈북 아동 연구의 양적인 성장이 일어나고 있다는 것이다. 특히 자연과학 연구 분야에 서는 최근 제 4 기간에 15 편의 논문이 발표되어, 18 편을 발표한 사회과학 분야와 비등한 결과를 나타내 보이고 있다. 제 2,3 기 간과 비교해볼 때 자연과학 분야의 논문 수는 약 2 배 이상 많 아졌다는 것을 알 수 있다. 뿐만 아니라 인문학 분야와 의약학 분야에서도 차츰 더 많은 수의 논문이 발표되고 있는데, 이러 한 결과를 통해 탈북 아동에 대한 관심이 사회과학 분야에서 다른 여러 연구 분야로 확산되었다는 것을 알 수 있다.

\section{연구 주제별 분포도}

연구 주제에 따라 논문의 수를 분석한 결과는 Table 6과 같다.

Table 6에 의하면, 가장 많은 연구가 이루어진 주제는 가
Table 6

Number of Papers by Research Theme (\%)

\begin{tabular}{llr}
\hline & \multicolumn{1}{c}{ Research theme } & $n(\%)$ \\
\hline 1 & General policy & $12(9.45)$ \\
2 & Psychology $\cdot$ Sexuality $\cdot$ Counseling & $26(20.47)$ \\
3 & Consciousness $\cdot$ Culture $\cdot$ Society & $16(12.60)$ \\
4 & Family $\cdot$ Welfare & $36(28.35)$ \\
5 & Education $\cdot$ Activity & $21(16.54)$ \\
6 & Behavioral Problems $\cdot$ Delinquency & $1(0.79)$ \\
7 & Health & $6(4.72)$ \\
8 & Other & $6(4.72)$ \\
9 & Mixed theme & $3(2.36)$ \\
\hline & Sum $(\%)$ & $127(100)$ \\
\hline
\end{tabular}

족·복지(36편, 28.35\%)였고, 심리·성·상담이 26편(20.47\%), 교육·활동 21 편(16.54\%), 의식·문화·사회 16편(12.60\%), 일 반정책 12 편(9.45\%), 건강 6편(4.72\%), 기타 6편(4.72\%) 및 문 
제·비행 1편(0.79\%) 순으로 조사되었다. 주제가 혼합되어 이 루어진 연구는 3편(2.36\%)이 있었다.

다수의 연구가 이루어진 주제 순으로 논문의 내용을 유목 화하여 분석하면 다음과 같다. 첫째, 가족-복지 주제에서는 탈 북 아동의 부모에 대한 연구가 많이 이루어졌다. "탈북 부모의 양육과 부모 역할'에 대한 연구가 다수로 이루어졌으며 프로 그램, 복지 정책 등 '부모 및 가족을 지원하는 방안’에 대한 연 구도 있었다. 또한 '가족 내 심리적 역동성이 유아에게 미치는 영향'에 대한 연구도 있었다. 이 중 주목해야 할 것은, 어머니 를 대상으로 하는 연구는 많이 있었으나 아버지를 단독적으로 연구한 논문은 극소수에 불과하다는 것이다.

둘째, 심리·성·상담 주제에서는 탈북 아동을 대상으로 하 는 상담-심리치료 기법에 대한 연구가 다수 이루어졌다. 사용 된 치료 기법으로는 미술치료가 가장 많았고 놀이치료, 음악 치료, 독서치료, 놀이와 미술의 통합치료 및 집단 상담이 있었 다. 또한 연구에서 다뤄진 심리적 특성으로는 사회·학교·심리 적 적응과 자아존중감이 가장 많이 연구되었고 사회적 기술 및 대인관계, 스트레스, 심리적 외상 및 불안 등이 연구 되었 다. 이 외에도 정서지능, 자기통제, 정서표현과 같은 정서적 영 역에 대한 연구도 이루어졌다.

셋째, 교육·활동 주제에서는 교육기관에서의 생활과 학업 성취도에 관한 연구가 많았다. 교육 프로그램을 개발하거나 그 효과를 알아보는 연구도 있었는데, 그 내용으로는 사회적 기술향상 프로그램, 국어 교육과 한국어 교육 프로그램, 문화 예술교육 프로그램, 민주시민교육 프로그램, 사회적응 멘터링 프로그램, 동요 지도, 무용 교육 프로그램 등이 있었다.

넷째, 의식·문화·사회 주제에서는 문화 및 사회 적응과 관
련된 연구가 많았다. 이 외에도 또래관계에 대한 연구나 사회 화, 놀이 등에 관한 연구도 이루어지고 있었다.

다섯째, 일반 정책 주제에서는 탈북 아동을 지원하는 정책 을 분석하고 발전 방향을 모색하는 연구가 많았다. 또한 통일 시대를 위한 교사 양성과 관련된 연구도 이루어지고 있었다.

여섯째, 건강 주제에서는 탈북 아동의 식생활과 성장 정도 를 분석한 연구와 구강 상태를 비롯한 건강 상태를 분석한 연 구, 건강 교육과 그 효과에 관한 연구가 이루어지고 있었다.

일곱째, 기타로 분류된 주제의 연구로는 다문화 가정 자녀 의 연구 동향 논문과 미디어와 문학작품에 나타난 탈북 아동 을 분석하는 연구가 있었다.

여덟째, 주제가 혼합되어 이루어진 연구에는 탈북 아동의 특성에 대해 광범위하게 다룬 연구들과 탈북 아동의 학교생활 과 정체성에 대해 함께 다룬 연구가 있었다.

아홉째, 문제·비행에 관한 주제에서는 탈북 아동의 분리경 험과 애착 양상 및 문제행동간의 관련성을 연구한 논문이 있 었다.

아래의 Table 7은 시간의 흐름에 따른 연구 주제의 추이를 분석한 결과이다.

Table 7을 통해 알 수 있는 연구 주제의 동향 변화를 기간 별로 분석하면 다음과 같다. 제 1 기간에 의식·문화.사회와 교 육·활동 연구 주제에서 탈북 아동에 관한 연구가 시작된 것을 알 수 있다. 이러한 추세는 제 2 기간에도 계속해서 지속되는 데, 이 두 가지 주제와 더불어 심리·성·상담과 가정·복지의 주 제에서도 다수의 연구가 이루어지기 시작한다. 제 3 기간부터 는 이전의 추세가 역전되어 가정·복지와 심리·성·상담 주제 에서 다수의 연구가 이루어졌고, 그동안 우위를 차지했던 의

Table 7

Number of Papers by Research Theme and Year

\begin{tabular}{|c|c|c|c|c|c|}
\hline Research theme Year & $\begin{array}{l}\text { The } 1 \text { period } \\
1999-2003 \\
\text { (5 years) }\end{array}$ & $\begin{array}{l}\text { The } 2 \text { period } \\
\text { 2004-2008 } \\
\text { (5 years) }\end{array}$ & $\begin{array}{l}\text { The } 3 \text { period } \\
2009-2013 \\
\text { (5 years) }\end{array}$ & $\begin{array}{l}\text { The } 4 \text { period } \\
2014-2017 \\
\text { (4 years) }\end{array}$ & Sum \\
\hline General policy & 0 & 1 & 6 & 5 & 12 \\
\hline Psychology $\cdot$ Sexuality $\cdot$ Counseling & 0 & 6 & 11 & 9 & 26 \\
\hline Consciousness $\cdot$ Culture $\cdot$ Society & 4 & 8 & 2 & 2 & 16 \\
\hline Family · Welfare & 0 & 6 & 14 & 16 & 36 \\
\hline Education $\cdot$ Activity & 3 & 6 & 8 & 4 & 21 \\
\hline Behavioral Problems . Delinquency & 0 & 0 & 0 & 1 & 1 \\
\hline Health & 1 & 1 & 3 & 1 & 6 \\
\hline Other & 0 & 2 & 1 & 3 & 6 \\
\hline Mixed theme & 1 & 0 & 1 & 1 & 3 \\
\hline Sum & 9 & 30 & 46 & 42 & 127 \\
\hline
\end{tabular}


식·문화·사회 주제의 연구는 소수로 이루어지는 결과를 보였 다. 마지막 제 4 기간에서는 주제별로 발표된 논문 수의 격차가 커지면서 기존 순위가 강화되는 경향을 보였다. 즉, 가정·복지 주제의 논문이 16 편으로 다수 발표되었으며, 그 뒤를 이어 심 리·성·상담(9편) 및 일반정책(5편) 주제에서 많은 논문이 발 표되었다.

\section{연구 방법별 분포도}

연구 방법별로 논문의 수를 분석한 결과는 아래의 Table 8 과 같다. Table 8 에 의하면, 탈북 아동 연구에서는 질적연구와 조 사연구, 실험연구의 방법이 다수로 사용되고 있음을 알 수 있 다. 구체적으로 살펴보면 질적연구가 36 편(28.35\%)으로 가 장 많았고, 그 다음으로 조사연구가 35편(27.56\%) 이루어졌 다. 질적연구와 조사연구의 비율을 합하면 $55.91 \%$ 로, 총 127 편의 논문 중 절반 이상이 질적연구와 조사연구로 이루어졌다 는 것을 알 수 있다. 뒤를 이어 실험연구도 다수로 이루어지고 있었으며(24편, $18.90 \%$ ), 문헌연구 13편(10.24\%), 혼합연구

Table 8

Number of Papers by Research Methods (\%)

\begin{tabular}{lr}
\hline \multicolumn{1}{c}{ Research methods } & $n(\%)$ \\
\hline Survey research & $35(27.56)$ \\
Experimental research & $24(18.90)$ \\
Comparative research & $1(0.78)$ \\
Literature research & $13(10.24)$ \\
Qualitative research & $36(28.35)$ \\
Development research & $6(4.72)$ \\
Mixed methods research & $12(9.45)$ \\
\hline \multicolumn{1}{c}{ Sum $(\%)$} & $127(100)$ \\
\hline
\end{tabular}

가 12 편(9.45\%), 개발연구 6편(4.72\%), 그리고 비교연구 1 편 $(0.78 \%)$ 순으로 이루어지고 있었다.

구체적인 연구 방법을 순위별로 분석하면 다음 일곱 가지 와 같다. 첫째, 가장 많이 사용된 연구방법인 질적연구는 대부 분 소수의 아동을 대상으로 하여 참여관찰이나 (심층)면담의 방법으로 이루어졌다. 둘째, 조사연구에는 설문조사의 방법을 활용한 연구가 많았으며 이에 대한 내용을 보충하거나 보완하 기 위해 연구 대상자들과 인터뷰를 하기도 하였다. 또한 연구 주제와 관련된 검사도구를 사용하여 실태조사를 실행하기도 하였다. 셋째, 실험연구의 경우 많은 수의 연구가 한 집단만을 연구 대상으로 설정하였으며, 교육·활동·치료 프로그램의 전 후 비교를 통해 효과를 검증하는 방식으로 이루어졌다. 몇 연 구는 연구 대상을 실험집단과 통제집단으로 나누어 설정하여 활동의 효과를 검증하기도 하였다. 넷째, 문헌연구는 선행 연 구나 통계자료를 비롯한 다양한 문헌을 통해 현재의 실태를 파악하고 분석하는 방법으로 이루어졌으며 이를 바탕으로 새 로운 과제나 개선 방향을 제시하기도 하였다. 다섯째, 혼합연 구는 대부분 문헌연구와 함께 그 외의 다른 연구방법을 병행 하여 사용하는 양상을 보였는데, 몇몇 소수의 연구들은 양적 연구와 질적연구의 방법을 병행하여 사용하기도 하였다. 여섯 째, 개발연구는 심리치료 프로그램이나 교육 프로그램, 적응 력 향상 등을 위한 각종 프로그램을 새롭게 개발하는 연구로 써, 실험연구와 같이 프로그램을 실제로 적용해본 후 사전-사 후를 비교하거나 참여자를 대상으로 하는 만족도 조사를 통해 프로그램의 효과를 검증해보는 과정이 연구에 포함되기도 하 였다. 일곱째, 비교연구는 Jeon (2016)의 연구로, 이주배경 청 소년을 위한 국내 정책을 대만, 일본과 비교한 연구이다. 이주 배경 청소년에는 탈북 아동과 청소년도 포함되어 있었다.

아래의 Table 9는 시간의 흐름에 따른 연구 방법의 추이를

Table 9

Number of Papers by Research Methods and Year

\begin{tabular}{|c|c|c|c|c|c|}
\hline Research methods & $\begin{array}{c}\text { The } 1 \text { period } \\
1999-2003 \\
\text { ( } 5 \text { years) }\end{array}$ & $\begin{array}{c}\text { The } 2 \text { period } \\
2004-2008 \\
(5 \text { years) }\end{array}$ & $\begin{array}{c}\text { The } 3 \text { period } \\
2009-2013 \\
(5 \text { years })\end{array}$ & $\begin{array}{c}\text { The } 4 \text { period } \\
2014-2017 \\
\text { ( } 4 \text { years) }\end{array}$ & Sum \\
\hline Survey research & 2 & 9 & 10 & 14 & 35 \\
\hline Experimental research & 0 & 5 & 13 & 6 & 24 \\
\hline Comparative research & 0 & 0 & 0 & 1 & 1 \\
\hline Literature research & 0 & 3 & 7 & 3 & 13 \\
\hline Qualitative research & 6 & 8 & 8 & 14 & 36 \\
\hline Development research & 0 & 2 & 3 & 1 & 6 \\
\hline Mixed methods research & 1 & 3 & 5 & 3 & 12 \\
\hline Sum & 9 & 30 & 46 & 42 & 127 \\
\hline
\end{tabular}


분석한 결과이다.

Table 9를 통해 알 수 있는 연구 방법의 동향 변화를 기간별 로 분석하면 다음과 같다. 탈북 아동 연구가 발표되기 시작한 제 1 기간에는 질적연구와 조사연구의 방법이 주로 사용되었다 는 것을 알 수 있다. 특히 질적연구 방법이 두드러지게 많이 사 용됨으로써 연구 방법에 있어 집중화 현상이 있었음을 알 수 있다. 반면, 제 2 기간은 연구 방법의 다양화와 분산화가 이루어 진 시기라 할 수 있다. 다양한 연구 방법들이 시도되기 시작하 였으며 특히 실험 연구의 비중이 높아진 것을 알 수 있다. 이와 더불어 조사연구 방법도 다수 사용되어, 가장 많이 사용된 연 구 방법으로 순위를 차지하게 된다. 이어지는 제3기간에서 주 목해야 할 점은 실험연구와 문헌연구 방법을 사용한 논문 수 의 증가이다. 실험연구의 논문이 급증하여 가장 많이 사용된 연구 방법으로 집계되었고, 문헌연구 역시 증가하여 이 시기 에 발표된 질적연구의 수와 어깨를 나란히 하게 되었다. 마지 막 제4기간에서는 조사연구와 질적연구가 압도적인 우위를 차지하면서 가장 많이 사용되는 연구 방법으로 분석되었다.

\section{논의 및 결론}

탈북 아동에 관한 연구의 동향 분석 결과를 기초로 논의하면 다음 다섯 가지와 같다.

첫 번째로 분석된 결과는 연구의 연도별 발표 현황에 관한 것이다. 탈북 아동 연구는 1999년 처음 발표된 이후로 2008년 에 연구의 수가 급증하는 시기를 거쳐, 2012년 이후부터 유지 되는 추세인 것으로 분석 되었다. 1999년부터 논문이 발표되 기 시작한 것은, 1997 년에 「북한이탈주민의 보호 및 정착지원 에 관한 법률이 제정되면서 탈북 아동에 대한 사회적 관심이 높아진 결과로 볼 수 있다. 이러한 양적 증가 추세는 탈북 청소 년에 관한 연구 동향(Yun, 2014)과 유사하다. 이는 탈북 아동 과 청소년의 적응과 발달이 우리 사회의 중요한 과제로 부각 되기 시작하였다는 것을 의미한다.

두 번째로 분석된 결과는 연구 대상 아동의 연령 분포에 관 한 것이다. 분석 결과, 유아기 아동을 대상으로 한 연구보다 초 등학령기 아동을 대상으로 한 연구가 많았으며, 유아기 연구 의 경우, 부모나 교사를 직접적 연구 대상으로 설정한 비율이 높았다. 이러한 연구 동향이 나타난 이유는 세 가지로 추론 가 능하다. 첫째, 유아기 아동이 초등학령기 아동에 비해 성인에 대한 의존도가 높아, 부모와 교사의 양육 행동에 비교적 많은 영향을 받는다는 발달심리학적인 차이 때문이다. 둘째, 유아
를 직접적인 연구 대상으로 설정할 때 발생할 수 있는 어려움 때문이다. 예를 들어 언어 사용 능력이 미숙하고 주의 집중 시 간이 짧은 유아를 연구 대상으로 설정할 경우, 초등학령기 아 동을 대상으로 하는 경우에 비해 연구 방법에 제한이 있을 수 있으며, 신뢰로운 결과를 도출하기 위해 더 많은 시간과 노력 이 소요될 수 있다. 마지막으로 유아기의 발달 및 적응 문제가 다른 연령대에 비해 비교적 사회적으로 부각되지 않는다는 점 (Y. M. Kim, 2002)이 이유가 될 수 있다.

세 번째로 분석된 결과는 연구 분야에 관한 것이다. 분석 결 과, 아동학 및 가족학을 포함하는 생활과학과 교육학, 심리과 학 분야에서 다수의 연구가 이루어졌고, 최근에는 그 외의 다 양한 분야에서 연구가 시도되고 있었다. 이를 탈북 청소년에 관한 연구 동향(Yun, 2014)과 비교해보면 아동과 청소년 연 구 간 차이가 있음을 알 수 있다. 탈북 청소년에 관한 연구에 서는 교육학(31.13\%) 분야와, 청소년학이 포함된 기타사회과 학 $(20.75 \%)$ 분야에서 많은 연구가 이루어진 반면 생활과학 (3.77\%)이나 심리과학(4.72\%) 분야에서는 소수의 연구만이 이루어졌기 때문이다. 이러한 차이는 두 가지 이유에서 근거 를 찾을 수 있다. 첫째, 연구 대상의 연령대가 다르기 때문이 다. 즉, 탈북 아동 연구 동향에서는 ‘아동학'이 포함되어 있는 '생활과학' 분야가 높게 나타난 반면, 탈북 청소년과 관련된 연 구 동향에서는 '청소년' 분야가 포함된 '기타사회과학' 분야가 높은 것으로 분석되었다. 둘째, 청소년 연구와는 달리, 탈북 아 동을 심리 치료나 가정과 관련하여 이해하려는 노력이 많았 기 때문이다. 이러한 차이와는 반대로, 교육학 분야에서는 아 동과 청소년 연구 모두 다수의 연구가 이루어진 것으로 분석 되었다. 이는 아동 . 청소년의 적응에 있어서 교육과 학습이 큰 비중을 차지하기 때문인 것으로 보인다(G.-H. Yoo et al., 2004; M. R. Park, 2002; J. S. Kim, 2004).

네 번째로 분석된 결과는 연구 주제에 관한 것이다. 탈북 아 동 연구에서는 가족·복지, 심리·성·상담, 교육·활동 주제에서 많은 연구가 이루어진 것으로 분석되었다. 상위 세 주제에 대 해 세부적으로 논의하면 다음과 같다. 첫 번째로 가족.복지 주 제는 탈북 아동의 적응과 발달에 부모와 가족이 중요한 영향 을 미친다는 것과, 생태학적인 관점에서 탈북 아동을 바라볼 것에 대한 시사점을 남긴다. 그러나 아동이 부모와 가족에게 영향을 받기만 하는 수동적인 객체로서 오인될 가능성이 있으 므로 아동이 가족 내에서, 혹은 개인의 발달에 대해 갖는 주체 적인 역할에 대해서도 연구가 필요하다. 한편 탈북 아동 부모 에 대한 연구 중, 대다수는 어머니에 대한 연구로 이루어져 있 었는데, 그 이유는 다음 두 가지로 분석될 수 있다. 첫째, 북한 
이탈주민의 성비가 남성보다 여성이 많기 때문이다. 이를 알 게 하는 자료로서 Ministry of Unification (2017)의 통계에 따르 면 여성 북한이탈주민의 비율은 $71 \%$ 에 해당한다. 이러한 현 황을 고려할 때 아버지의 수보다는 어머니의 수가 많을 것이 라 추측할 수 있다. 둘째, 북한이탈주민 가정의 양육문화에서 근거를 찾을 수 있다. 북한의 가부장적인 문화에 익숙해져 있 는 탈북 가정에서는 대부분의 양육을 어머니가 담당하고 있는 데(Hong, 2003), 이러한 이유로 탈북 아동의 어머니에 대한 연 구가 아버지에 대한 연구보다 많은 것이라 해석할 수 있다. 하 지만 아버지 역할에 대한 남북의 문화적 차이에도 불구하고 (T. S. Kim, 2014; Noh, 2017; J. H. Oh, 2017) 아버지도 탈북 아 동에게 지대한 영향을 미칠 수 있으므로(Bae, 2017), 아버지의 역할 적응과 양육에 대한 연구도 적극적으로 실행되어야 할 필요가 있다.

두 번째로 많은 연구가 이루어진 심리·성-상담 주제에서는 상담 및 심리치료 프로그램을 실행한 후 효과를 검증하는 내 용의 연구들이 다수 있었는데, 미술·놀이·음악-독서치료, 통 합치료, 집단 상담과 같은 치료기법을 사용한 것으로 분석되 었다. 다양한 상담-심리 치료 기법 중 미술과 놀이, 음악, 독서 등의 방법을 활용하는 '예술치료' 기법들을 사용한 것은 연구 대상이 아동이라는 것과 관련 있을 것이다. 특히나 언어적 표 현이 미숙한 탈북 아동의 경우, 대화보다는 예술 경험을 통해 감정과 생각을 표현하는 것이 효과적이기 때문이다.

세 번째로 다수를 차지한 교육-활동 주제는 크게 두 가지로 나눌 수 있는데 그 중 첫 번째는 유아교육기관과 학교에서의 생활 및 적응에 관한 연구이다. 일반적으로 탈북 아동들이 처 음으로 경험하게 되는 남한 사회는 학교와 같은 교육기관이라 할 수 있다. 그렇기 때문에 이와 관련된 연구들은 남한 사회에 서 탈북 아동이 겪게 되는 적응의 과정을 구체적이고 심도 있 게 이해할 수 있도록 돕는다는데 의의가 있다. 두 번째로 교육 활동과 프로그램을 적용하고 효과를 알아보는 연구들이 있었 는데, 이러한 연구들에 대해 논의 되어야 할 점은 두 가지이다. 첫째, 대부분의 프로그램이 '초등학생'인 ‘탈북 아동’만을 대상 으로 하고 있다는 것이다. 탈북 아동의 성공적인 적응을 위해 서는, 탈북 아동뿐만 아니라 그와 함께 생활하는 다른 구성원 의 역할 또한 중요함에도 불구하고( Bourhis, Moise, Perreault, \& Senécal, 1997; J.-H. Park, 2008; Y. M. Kim, 2002) 아직까지는 탈북 아동과 함께 생활하는 또래나 교사를 대상으로 하는 프 로그램은 극소수인 것으로 분석되었다. 특히, 교육 현장에 탈 북 아동과 통합 교육에 대한 전문적 지식을 갖춘 교사가 소수 라는 현실을 고려할 때(I. K. Park, 2006; G.-H. Yoo et al., 2004;
B.-M. Lee, 2005), 그들을 지원할 수 있는 연구가 미비한 것은 아쉬운 점이라 할 수 있다. 둘째, 프로그램의 종류가 한정되어 있어, 실제 통합 환경에서 탈북 아동 교육에 적용하기에는 제 한적이었다. 특히 탈북 아동들이 겪는 가장 큰 어려움 중 하나 가 한국어 사용에 관한 것임(B.-M. Lee, 2004; K. Y. Lee, 2014; J. Kang, 2008)에도 불구하고 아직까지 이에 대해 다루고 있는 연구의 수가 절대적으로 부족한 실정이어서, 탈북 아동 개인 이 가지는 다양한 한국어 수준에 따라 체계적인 지원을 하기 어려운 상황이라 할 수 있다.

앞서 제시한 세 가지 연구 주제와는 달리 문제·비행에 관 한 연구와 건강에 관한 연구는 매우 소수로 이루어졌음을 확 인할 수 있었다. 이는 탈북 청소년 관련 연구 동향(Yun, 2014) 과 비슷한 양상이다. 문제·비행으로 분류되는 연구가 적은 것 은, 탈북 아동들의 심리·행동적 특성을 ‘문제’나 ‘비행'으로 정 의하지 않고, '적응'의 한 과정으로 이해하려는 노력의 일환일 수 있다. 탈북 아동이 가지는 특성을 문제나 비행으로 정의할 때, 그들에 대한 사회적인 낙인과 편견이 생길 수 있기 때문이 다. 반면 건강 주제에서는 더 많은 연구가 실행될 필요가 있다. 왜냐하면 탈북 아동의 발달과 적응에 건강 상태가 미치는 영 향이 크기 때문이다. 많은 탈북 아동들은 탈북과 입국 과정에 서 심각한 영양 부족과 열악한 보건 환경을 경험하곤 한다. 이 로 인해 유발되는 신장과 체중의 미달과 각종 질병은 적응에 부정적인 영향을 미치기도 한다. 하지만 S. Park (2000)에 의하 면 국내에 입국한 탈북 아동.청소년들은 어린 시절 영양결핍 으로 인해 발생한 발달의 차이를 메우는 '따라 잡기(catch-up)' 성장 패턴을 보인다. 이와 관련된 실태를 파악하려는 노력과 함께 그들의 성장 과정을 추적하는 연구는 건강.보건 영역에 서 탈북 아동을 지원하기 위한 근거로 활용될 수 있을 것이다.

다섯 번째로 분석된 결과는 연구 방법에 관련된 것이다. 분 석 결과, 질적연구와 조사연구가 다수로 이루어졌다. 이러한 동향이 나타난 이유는 크게 두 가지로 설명할 수 있다. 첫째, 질적연구와 조사연구 방법이 가지는 고유한 연구적 가치 때문 이다. 질적연구는 자연적 상황에서 개별 탈북 아동들의 적응 과 생활 양상을 심층적으로 바라볼 수 있도록 도우며, 조사연 구는 탈북 아동에 대한 풍부한 자료를 제공한다는 점에서 가 치 있다. 이러한 연구방법들은 인위적이지 않은 생활세계에서 탈북 아동에 대한 실증적 정보를 제공한다는 점에서 의의가 있다. 두 번째 이유는, 탈북 아동이라는 연구 대상을 표집하고 지속적으로 접촉하는 것이 쉽지 않기 때문이다. 이러한 현실 적인 문제로 인해, 소수의 사례를 대상으로 하는 질적연구나, 연구자와의 접촉을 최소화할 수 있는 조사연구가 주된 방법으 
로 사용할 여지가 있다. 하지만 언어 사용에 어려움을 겪는 탈 북 아동을 대상으로 설문 조사나 인터뷰를 실시할 경우 신뢰 로운 결과를 얻지 못할 가능성이 높다. 그러므로 유아와 초등 학생이라는 발달적 특성과 한국어 사용에 미숙할 가능성이 높 다는 탈북 아동의 특성을 고려하여 그들에게 적합한 연구 방 법을 고안하고 이를 바탕으로 연구에 접근해야 할 것이다. 한 편, 소수의 연구가 이루어진 개발연구의 경우, 현장에서 탈북 아동을 실제적으로 지원하는데 도움이 될 수 있으므로 활발히 연구되어야 하며, 비교연구 역시 탈북 아동의 특수성을 이해 하고 지원 방안을 강구하는데 도움이 되므로 적극적으로 연구 되어야 할 필요가 있다.

지금까지 분석한 결과를 토대로 후속 연구를 제언하면 다 음 다섯 가지와 같다.

첫째, 유아를 대상으로 하는 연구가 확대되어야 한다. 연구 동향 분석 결과, 유아와 관련된 연구의 수는 상대적으로 초등 학령기 연구에 비해 적었을 뿐만 아니라, 대부분이 부모를 비 롯한 가정과의 연계선 상에서, 이에 영향을 받는 객체로서 연 구되는 경우가 많았다. 실제로 유아를 연구 대상으로 설정하고 심도 있게 연구한 논문은 소수에 불과했다(J. Kang, 2008, 2010, 2011; Y. M. Kim, 2002; H. J. Kim, 2015; B.-M. Lee, 2003, 2004; I. Lee, 2012). 어린 연령의 탈북 아동이 증가하고 있는 현 실태를 고려할 때(Ministry of Unification, 2018), 유아기의 탈북 아동을 대상으로 하는 연구가 더 많이 이루어져야 할 것이다. 더불어 탈북 유아의 발달적 특성을 고려하여 신뢰로운 연구 결과를 도 출할 수 있는 연구 방법에 대한 후속연구도 필요하다.

둘째, 부모에 대한 연구 중, 아버지를 대상으로 하는 연구가 확대되어야 할 필요가 있다. 현대의 남-북한 사회가 가지는 부 모 역할에 대한 문화적 간극과 그로 인한 혼란은 어머니보다 아버지에게 더 크게 느껴질 수 있다. 왜냐하면 북한 가정은 아 버지를 중심으로 하는 확고한 위계질서와 가부장적 문화를 가 지고 있는데, 이는 현대 남한 사회가 지향하는 따뜻하고 자상 한 아버지상과 큰 차이가 있기 때문이다(J. H. Oh, 2017; B.-M. Lee, 2005). 그러므로 탈북 아동의 아버지를 대상으로 하는 연 구가 더 깊이 있게 다뤄져야 하며 특히 아버지로서의 역할과 정체감에 대한 연구가 심도 있게 이루어져야 한다.

셋째, 탈북 아동을 비롯한 다양한 사회 구성원이 실제 현장 에서 활용할 수 있는 교수.학습 방법과 복지 프로그램 개발 연 구가 필요하다. 하나원에서 퇴소한 대부분의 탈북 아동들은 남한의 교육·복지 기관에서 남한 아동 및 성인들과 함께 생활 하게 된다. 그럼에도 불구하고 현재의 교육-복지 현장에는 탈 북 아동과 통합 교육에 대한 충분한 이해가 부족한 실정이다.
선행연구들(L.-H. Oh, 2003; B.-M. Lee, 2004)에 의하면 탈북 아동의 교육·보육 기관 적응에 또래가 지대한 영향을 미치므 로, 프로그램의 대상을 탈북 아동으로 제한할 것이 아니라 그 와 함께 생활하는 남한 아동들로 확대할 필요가 있다. 예를 들 어, 탈북 아동을 만나기 전에 남한 아동들이 통합 교육을 준비 할 수 있도록 돕는 프로그램이나 탈북 아동과의 만남 이후에 다문화적 환경을 조성할 수 있도록 지원하는 프로그램이 필요 할 것이다. 또한 현장의 교사들도 탈북 아동과 통합 교육에 대 한 이해 아래 교사의 역할을 적절히 수행할 수 있도록 돕는 교 사 연수 프로그램이 개발되어야 하며, 현장에서 학생들을 대 상으로 직접 활용할 수 있는 다양한 교육 프로그램이 개발되 어야 할 것이다. 한편, 제 3 국에서 출생하여 한국어를 능숙하게 사용하지 못하는 탈북 아동과, 북한말과의 차이로 인해 언어 사용에 혼란을 겪는 탈북 아동을 위해 한국어 교육 프로그램 역시 개발될 필요가 있다(H. Han, 2015).

넷째, 일회적이고 단기적인 연구를 넘어서 장기적인 관점 에서 탈북 아동의 삶과 변화를 조망하는 연구가 필요하다. 현 재의 연구들 대부분은 일 년 이내의 기간, 특히 6개월 이내의 기간 동안 자료 수집과 연구가 진행되는 양상을 보였다. 특정 시점에서 아동이 보이는 단기적인 변화의 모습을 관찰하는 것 도 의미 있지만 장기적인 종단 연구를 통해 보다 깊이 있는 이 해가 가능하기도 한다. 예를 들어, 시간이 지남에 따라 탈북 아 동들이 거치게 되는 적응의 과정이나 남한 사회 구성원으로서 의 정체감을 형성해 가는 과정, 자아존중감이나 불안.스트레 스와 같은 심리적 특성들의 변화, 정치·문화·경제 등과 관련 된 가치관의 변화, 신체 발달의 변화와 따라 잡기 성장 패턴 등 과 관련된 내용을 장기적으로 연구한다면 탈북 아동의 삶에 대한 깊이 있는 이해가 가능해질 것이다.

다섯째, 다양한 배경과 경험에 따라 각 탈북 아동이 가지고 있는 특수성을 밝혀내는 비교 연구가 필요하다. 탈북 아동의 특수성을 밝히는 연구는 그들을 특수 집단으로 분류하고 외인 (外人)화 하는 것이 아닌, 다른 특성을 가진 그들의 모습을 인 정하고 이해하는 것이 목적이 되어야 하며 더 나아가 다양성 을 존중하는 사회적 분위기를 형성하는데 목적을 두어야 한 다. 탈북 아동의 특수성은 다양한 집단과의 비교를 통해 이해 될 수 있는데, 크게 세 가지로 분류할 수 있을 것이다. 먼저, 남 한 아동과의 비교를 통해 탈북 아동의 특수성을 이해할 수 있 다. 남한 아동과 탈북 아동의 생활 태도, 삶의 양식, 심리·정서 적 특성, 발달 패턴 등의 공통점과 차이점을 이해하는 것은 탈 북 아동의 적응과 사회통합의 차원에서 의미 있는 연구가 될 것이다(Yun, 2014). 두 번째로, 다문화 아동과의 비교를 통해 
탈북 아동의 특수성을 이해할 수 있다. 현재 많은 다문화 연구 들이 탈북 아동을 다문화 아동의 범주 안에 포함하여 연구하 고 있다. 물론 분단 역사가 70년이 된 남북한의 문화적 차이는 타문화와 비교해도 다르지 않을 정도로 커져버린 것이 현실이 다. 하지만 탈북 아동들은 다른 다문화 아동과는 구별되는 특 수성을 가지고 있기도 하다. 예를 들어, 북한에 있을 때 경험했 던 정치·경제적 체제와 가치관, 탈북과 입국 과정에서 겪었던 어려움, 한민족 내에서 경험하게 되는 이질감과 소외감 등 다 른 인종의 부모를 가진 아동과는 다른 특수성을 가지고 있다. 이에 대한 고민은 탈북 아동이 현재 다문화 사회 내에서, 그리 고 통일을 준비하는 특수한 한반도 상황 가운데서 어떤 위치 를 가지고 있는지 이해하게 할 것이다. 마지막으로, 탈북 아동 내의 하위집단 간 비교를 통해 개인이 가지는 특수성을 이해 할 수 있다. 동일하게 ‘탈북 아동’으로 명명된다 하더라도 그들 개인이 가지는 다양한 배경과 경험 의해 삶의 모습에서 큰 차 이가 나타나기 때문이다(J. Yoo, 2015; J. Kang, 2010). 북한. 중 국을 비롯한 제 3 국·남한 등 출생지가 어딘지에 따라 아동 개 인이 가지게 되는 과거의 경험에는 큰 차이가 있으며, 이로 인 해 심리·정서적 상태와 한국어 사용 능력 등에서 크고 작은 차 이가 발생하기도 한다. 또한 양쪽 부모 중 어느 쪽이 북한 출신 인지, 북한 출신이 아닌 부모가 있다면 그 부모는 어느 국적을 가졌는지, 어느 연령에 탈북과 입국을 경험했는지, 정착 시기 는 얼마나 되었는지 등 수많은 요인들에 의해 탈북 아동 개인 간 특수성이 발생하게 된다. 특히, 북한이탈주민을 부모를 둔 남한 출생의 아동이 증가하고 있음에도 이에 대한 연구가 부 족한 실정이므로(J. Yoo, 2015), 이들이 가진 특수성을 밝힐 수 있는 연구가 실행되어야 할 것이다.

본 연구는 지금까지 이루어진 탈북 아동 연구들의 동향을 분석하고 앞으로 이루어져야 할 연구의 방향을 제언했다는 점 에서 의의를 가진다. 또한 아동 연령을 대상으로 하는 탈북 연 구들을 분석함으로써 기존에 이루어졌던 북한이탈주민에 관 한 연구 동향 분석(G. T. Park, 2014; Yun, 2014)을 구체화했다 는 점에서 의의가 있다. 특히, 그동안 동향 연구에 포함되지 않 았던 유아를 대상으로 하는 연구들까지 포함했다는 점에서 의 미가 있다.

그럼에도 불구하고 본 연구는 다음과 같은 제한점을 가진 다. 첫째, 중국 거주 탈북 아동을 대상으로 하는 연구와 대상 아동의 연령이 불명확한 연구를 분석 논문에서 제외하였다. 둘째, 검색 시 열람 불가 상태인 논문들은 연구 대상에서 제외 하였다. 향후 연구에서는 누락된 자료들을 포함함으로써 탈북 아동에 관한 동향 연구를 보완할 수 있을 것이다.

\section{Notes}

This article was presented at the 2017 Annual Fall Conference of the Korea Open Association for Early Childhood Education.

\section{Conflict of Interest}

No potential conflict of interest relevant to this article was reported.

\section{References}

\section{In English}

Bourhis, R. Y., Moise, C. L., Perreault, S. \& Senécal, S. (1997). Towards an interactive acculturation model: A social psychological approach. International Journal of Psychology, 32(6), 369-386. doi:10.1080/002075997400629

\section{In Korean}

Bae, M. R. (2017). Childcare experience of North Korean female defectors living in South Korea (Doctoral dissertation). Retrieved from http://www.riss.kr/link?id=T14469877

Choi, D. S., \& Park, Y. J. (2011). Research trend and priority subject of policy research on north korean defector : Soulsearching and communication beyond quantitative growth. Korean Journal of International Relations, 51(1), 187-215.

Han, H. (2015). Primary research on Korean language education for North Korean refugee children from the third countries. Journal of The Society of Korean Language and Literature, 73(0), 327-358.

Hong, J. E. (2003). Analysis of North Korean defectors parent's changes and problems in child-rearing (Master's thesis). Retrieved from http://www.riss.kr/link?id=T10016616

Huh, J., Yi, S. Y., Han, H. Y., O, K. S., \& Jung, H. (2017). Trend analysis and tasks of the research on North Korea education. Andragogy Today: International Journal of Adult \& Continuing Education, 20(4), 1-26.

Jeon, S. Y. (2016). (A) Study on policy for young immigrant in Korea : A comparison between Taiwan and Japan (Master's thesis). Retrieved from http://www.riss.kr/link?id=T13994779

Kang, J. (2008). Sae-teo-min children's life at childcare center. Journal of Educational Studies, 39(1), 45-66.

Kang, J. (2010). Kindergarten adaptation process and play features of 
three North Korean children defectors : A focus on their initial settlement period in the Hanawon. (Doctoral dissertation). Retrieved from http://www.riss.kr/link?id=T11926634

Kang, J. (2011). Experiences of North Korean defectors' young children during their escape journeys prior to arrival in South Korea. Korean Journal of Early Childhood Education, 31(4), 59-80.

Kim, H. J. (2015). North Korean refugee children's separation experiences, attachment aspect and behavioral problems (Master's thesis). Retrieved from http://www.riss.kr/ link?id=T13924661

Kim, J. S. (2004). A study on the initial adjustment of the North Koream defecting children in South Korea (Master's thesis). Retrieved from http://www.riss.kr/link?id=T9494148

Kim, M. J. (2014). A qualitative study about the prejudice of South Korean children against the North Korean refugee youths (Master's thesis). Retrieved from http://www.riss.kr/ link?id=T13568752

Kim, S.-H. (2017). A study of self-esteem improvement for North Korean refugees adolescents' school life adjustmen (Master's thesis). Retrieved from http://www.riss.kr/link?id=T14448442

Kim, T. S. (2014). A study on the adaptation of North Korean defectors in South Korea (Master's thesis). Retrieved from http://www.riss.kr/link?id=T13421958

Kim, Y. M. (2002). A case study on the South Korean life resilence for North Korean child defector (Master's thesis). Retrieved from http://www.riss.kr/link?id=T10207202

Kim, Y. Y. (2002). School life and identity of North Korean refugee children in South Korea (Master's thesis). Retrieved from http://www.riss.kr/link?id=T8309302

Korea Hana Foundation (2016). 2015 Bukanitaljumin sahoejosa [2015 북한이탈주민 사회조사]. Seoul: Korea Hana Foundation.

Korea Hana Foundation (2017). 2016 Talbukcheongsonyeon siltaejosa [2016 탈북청소년 실태조사]. Seoul: Korea Hana Foundation.

Lee, B.-M. (2003). Field studies on the adaptation processes for North Korean Refugee Children at an Educational Institute (Hanawon) in South Korea. Korean Journal of Early Childhood Education, 23(2). 115-145.

Lee, B.-M. (2004). A study on a North Korean refugee child's life and adaptation through making the best friend at South Korean educare center. Journal of Korean Council for Children \& Rights, 8(3), 353-387.

Lee, B.-M. (2005). A qualitative research on North Korean refugee parents' adaptation process as parents in South Korea. Journal of Korean Council for Children \& Rights, 9(4), 691-726

Lee, I. (2012). Development and effect of health education program for preschooler defected from North Korea (Doctoral dissertation). Retrieved from http://www.riss.kr/link?id=T12774820

Lee, K. Y. (2014). Policy analysis of and effective alternatives to current assitance programs for North Korean defecting adolescents and NK defectors' children: Unaccompanied minors, children born in the 3rd countries, and those born in South Korea. Seoul: Korea Hana Foundation.

Lee, M. H. (2011). Research trends analysis on child abuse (Master's thesis). Retrieved from http://www.riss.kr/ link?id=T12581052

Lee, M. Y. (2015). An integrative literature review on integration support for North Korean migrants in South Korea. Korean Journal of Family Social Work, 49, 39-69.

Lee, Y. M. (2015). Research trends regarding siblings without disabilities : Focus on articles in communication journal (Master's thesis). Retrieved from http://www.riss.kr/link?id=T13715525

Lee, Y. S., Son, J. H., \& Choi, Y. J. (2012). The Analysis of the research trend of dissertation on youth science. Journal of Future Oriented Youth Society, 9(3), 19-35.

Ministry of Unification. (2017). 2017 Unification white paper. Seoul: Ministry of Unification.

Ministry of Unification. (2018). 2018 Unification white paper. Seoul: Ministry of Unification.

National Research Foundation of Korea. (2016). Haksuryeongubunyabullyupyo [Classification table of academic research field]. Retrieved July 1, 2017, from http://www.nrf.re.kr/biz/ doc/class/view?menu_no $=323$

Noh, J. H. (2017). The process of relation change between husband and wife of North Korean defectors: Focusing on the experience of North Korean women (Master's thesis). Retrieved from http://www.riss.kr/link?id=T14537235

Oh, J. H. (2017). A research for the child rearing experiences of the fathers who residents escaping from North Korea, have babyhood children (Master's thesis). Retrieved from http:// www.riss.kr/link?id=T14429281

Oh, L.-H. (2003). (A) Case study about adjustment in South Korea of youth defector (Master's thesis). Retrieved from http:// www.riss.kr/link?id=T9129161

Park, G. T. (2014). Trends and tasks of research on North Korean defectors's adaptation. The Study of Job and Employment Service, 9(2), 15-29.

Park, I. K. (2006). A study on teachers' role in the adjustment of North Korean youth defectors (Master's thesis). Retrieved from http://www.riss.kr/link?id=T10873370

Park, J.-H. (2008). The factor influencing North Korean defection children's South Korean social adaptation (Doctoral dissertation). Retrieved from http://www.riss.kr/link?id=T11203760

Park, J.-R., \& Kang, D. W. (2011). A study on female North Korean defectors: Trends, controversial issues, and tasks. North Korean Studies Review, 15(2), 1-24.

Park, M. R. (2002). A study on the adaption of the North Korean children to South Korean society (Master's thesis). Retrieved from http://www.riss.kr/link?id=T8687178 
Park, S. (2000). An assessment of the long-term effects of food crisis on children's growth and development in North Korea. Korean Cultural Anthropology, 33(1), 207-240.

Song, H. J. (2008). The effect of art therapy on decreasing the internal stress and adaptation to school: Focusing on the children defectors from North Korea (Master's thesis). Retrieved from http://www.riss.kr/link?id=T11959702

Yang, O.-K., \& Yun, J.-H. (2017). Scoping review on the mental health studies of North Korean detectors in Korea. Multiculture \& Peace, 11(2), 172-196.

Yoo, G.-H., Bang, E.-R., \& Han, E.-J. (2004). A case study on school achievement and social adaptation of North Korean refugee children \& adolescents. Journal of Korean Home Management Association, 22(5), 185-196.

Yoo, J. (2015). Characteristics of children of North Korean defectors : Focusing on elementary school students born in South Korea. (Master's thesis). Retrieved from http://www.riss.kr/
link?id=T13701133

Yun, H.-S. (2014). Research trend and priority subject of research on North Korean migrant youth in South Korea. Korean Journal of Youth Studies, 21(11), 125-149.
Young Suk Yong

Suk Ja Kim https://orcid.org/0000-0002-9004-8459

https://orcid.org/0000-0003-3759-4271
Received April 30, 2018 Revision received June 24, 2018

Accepted August 2, 2018 